\title{
Dopamine Is Necessary for Cue-Dependent Fear Conditioning
}

\author{
Jonathan P. Fadok, ${ }^{1,2}$ Tavis M. K. Dickerson, ${ }^{2}$ and Richard D. Palmiter ${ }^{2}$ \\ ${ }^{1}$ Graduate Program in Neurobiology and Behavior and ${ }^{2}$ Department of Biochemistry and Howard Hughes Medical Institute, University of Washington, \\ Seattle, Washington 98195
}

Dopamine (DA) is implicated in many behaviors, including motor function, cognition, and reward processing; however, the role of DA in fear processing remains equivocal. To examine the role of DA in fear-related learning, dopamine-deficient (DD) mice were tested in a fear-potentiated startle paradigm. DA synthesis can be restored in DD mice through administration of 3, 4-dihydroxy-L-phenylalanine (L-Dopa), thereby permitting the assessment of fear processing in either a DA-depleted or -replete state. Fear-potentiated startle was absent in DD mice but could be restored by L-Dopa administration immediately after fear conditioning. Selective viral-mediated restoration of DA synthesis within the ventral tegmental area fully restored fear learning in DD mice, and restoration of DA synthesis to DA neurons projecting to the basolateral amygdala restored short-term memory but not long-term memory or shock sensitization. We also demonstrate that the $\mathrm{DA} \mathrm{D}_{1}$ receptor $\left(\mathrm{D}_{1} \mathrm{R}\right)$ and $\mathrm{D}_{2}$-like receptors are necessary for cue-dependent fear learning. These findings indicate that DA acting on multiple receptor subtypes within multiple target regions facilitates the stabilization of fear memory.

\section{Introduction}

The neuromodulator dopamine (DA) is important for rewardrelated learning and drug-seeking behavior (Schultz, 2002; Wise, 2004), and accumulating evidence suggests that DA may also be important for fear-related learning (Lamont and Kokkinidis, 1998; Guarraci et al., 1999, 2000; Greba and Kokkinidis, 2000; Greba et al., 2001; Pezze and Feldon, 2004; de Oliveira et al., 2006). DA neurons of the ventral midbrain project to limbic brain areas important for fear learning, and DA levels in these brain areas increase during aversive events (Abercrombie et al., 1989; Kalivas and Duffy, 1995; Doherty and Gratton, 1997; Inglis and Moghaddam, 1999). Additionally, some midbrain DA neurons increase their firing rates to aversive stimuli and predictive cues (Guarraci and Kapp, 1999; Horvitz, 2000; Joshua et al., 2008). Furthermore, DA has been shown to facilitate long-term potentiation, a key neural correlate of memory, in areas critical for fear learning, such as the hippocampus and amygdala (Bissière et al., 2003; Lemon and Manahan-Vaughan, 2006; Swant and Wagner, 2006).

Despite the progress made relating DA neuron physiology to fear, the precise role of DA and its cognate receptors in fearrelated learning remains unresolved. Injections of $\mathrm{DA}_{1}$ recep-

\footnotetext{
Received April 3, 2009; revised June 15, 2009; accepted July 6, 2009.

This investigation was supported in part by Public Health Service National Research Service Award T32 GM07270 from the National Institute of General Medical Sciences, and National Institutes of Health-National Institute of General Medical Sciences Grant 4 R25 GM 058501-05. We thank Ilene Bernstein, Lisa Beutler, Charles Chavkin, and Larry Zweifel for helpful comments on this manuscript, Albert Quintana for help on histology, and Valerie Wall for mouse colony maintenance. We also thank Dr. Miguel Chillon (Vector Production Unit of Center of Animal Biotechnology and Gene Therapy at Universitat Autonoma of Barcelona, Barcelona, Spain) for CAV2 and Matthew During for AAV1 virus.

Correspondence should be addressed to Richard D. Palmiter, Howard Hughes Medical Institute and Department of Biochemistry, Box 357370, University of Washington, Seattle, WA 98195. E-mail: palmiter@u.washington.edu. DOI:10.1523/JNEUROSCI.1616-09.2009

Copyright $\odot 2009$ Society for Neuroscience $\quad$ 0270-6474/09/2911089-09\$15.00/0
}

tor $\left(\mathrm{D}_{1} \mathrm{R}\right)$-like antagonists systemically, or into the amygdala, have been shown to block acquisition or expression of fearrelated learning; however, others have shown that these drugs have no effect (Guarraci et al., 1999; Greba and Kokkinidis, 2000; de Oliveira et al., 2006). Additionally, $\mathrm{D}_{1} \mathrm{R}$-like agonists have been shown to either enhance or have no effect on fear conditioning (Guarraci et al., 1999; Greba et al., 2000; Inoue et al., 2000; de Oliveira et al., 2006). Analogous discrepancies have been found in studies using agonists or antagonists for $\mathrm{D}_{2} \mathrm{R}$-like receptors (Guarraci et al., 2000; Greba et al., 2001; Ponnusamy et al., 2005; de Oliveira et al., 2006). These discrepancies could be attributable to behavioral methodology, dose-dependent effects of drugs injected, or differences in choice of pharmacological agents. For example, DA receptor antagonists vary widely in their selectivity; thus, although some studies may be more selectively antagonizing $\mathrm{D}_{2}$ receptors, others may be more broadly antagonizing $\mathrm{D}_{2}$, $\mathrm{D}_{3}$, and $\mathrm{D}_{4}$ receptors (Missale et al., 1998).

To elucidate the role of DA in fear-related learning, we used dopamine-deficient (DD) mice, as well as mice lacking either the $\mathrm{D}_{1} \mathrm{R}$ or $\mathrm{D}_{2} \mathrm{R}$, and tested them in a fear-potentiated startle paradigm. Fear-potentiated startle is a pavlovian-fear conditioning paradigm in which a neutral stimulus elicits increases in the acoustic startle response after pairings with a footshock (Koch, 1999). Fear-potentiated startle is an ideal paradigm for these studies because it does not depend on an assessment of freezing behavior, which is difficult to measure in hypoactive DD mice (Zhou and Palmiter, 1995). Because DD mice can be studied in either a DA-depleted or DA-replete state, they provide an ideal opportunity to study the role of DA in learning and memory formation. Furthermore, using virus-mediated delivery of Cre recombinase, DA signaling can be selectively restored to specific target regions by reactivation of a tyrosine hydroxylase $(T h)$ allele in DD mice (Hnasko et al., 2006). Selective restoration of DA to 
specific target areas allows for the assessment of brain regions regulated by DA signaling during fear conditioning.

\section{Materials and Methods}

Animals and treatments. DD mice were generated as described previously (Hnasko et al., 2006). Briefly, DD $\left(T h^{f s / f_{s}} ; D b h^{T h /+}\right)$ mice carry two nonfunctional $T h$ alleles, which have been inactivated via insertion of the neomycin resistance NeoR gene flanked by lox P sites into the first intron of the Th gene. These mice also carry one intact dopamine $\beta$-hydroxylase $(D b h)$ allele and one $D b h$ allele with a targeted insertion of the Th gene. Control animals carry at least one intact $T h$ allele and one intact $D b h$ allele. Levels of non-dopaminergic catecholamines are normal in DD animals, and levels of all catecholamines are normal in control animals (Zhou and Palmiter, 1995; Szczypka et al., 1999). Mice were maintained on a mixed C57BL/ $6 \times 129 / \mathrm{Sv}$ genetic background. Because of severe hypophagia, DD mice were injected daily (intraperitoneally) with 3, 4-dihydroxy-L-phenylalanine (L-Dopa) at $50 \mathrm{mg} / \mathrm{kg}$ at a volume of $33 \mu \mathrm{l} / \mathrm{g}$ (Zhou and Palmiter, 1995), starting at approximately postnatal day 10. These injections restore DA function for 8-10 h (Szczypka et al., 1999). $\mathrm{D}_{1} \mathrm{R}$ knock-out $(\mathrm{KO})$ and $\mathrm{D}_{2} \mathrm{R} \mathrm{KO}$ mice have been described previously (Drago et al., 1994; Kelly et al., 1997). Both strains were maintained on a C57BL/6 background. Because of growth retardation in $\mathrm{D}_{1} \mathrm{R}$ KO mice, they were weaned at 4 weeks and then fed moistened chow to promote growth. All animals were genotyped by PCR analysis. Male and female mice were subjected to behavioral testing between the ages of 2-5 months. All mice were housed under a $12 \mathrm{~h}$ light/dark cycle in a temperature-controlled environment with food (5LJ5; PMI Feeds) and water available ad libitum. All behavioral experiments were conducted during the light cycle. All mice were treated in accordance with guidelines established by the National Institutes of Health and the University of Washington Institutional Animal Care and Use Committee.

To assess whether other $\mathrm{D}_{2}$-like receptors are important for fear learning, $\mathrm{D}_{2} \mathrm{R}$ KO mice were administered the $\mathrm{D}_{2}$-like antagonist eticlopride (Sigma) at $0.5 \mathrm{mg} / \mathrm{kg}$ (intraperitoneally). Eticlopride was dissolved in $0.9 \%$ saline and was given at a final volume of 10 $\mu \mathrm{l} / \mathrm{g}$. $\mathrm{D}_{2} \mathrm{R}$ wild-type (WT) mice were injected with vehicle.

Apparatus. Sound-attenuating startle chambers (SR-Lab; San Diego Instruments) were used to measure prepulse inhibition, startle responses, and fear-potentiated startle. For startle responses, 651 -ms readings were taken, starting at pulse onset. To measure the response to footshock, $5001-\mathrm{ms}$ readings were taken, starting at shock onset. The peak amplitude of the response was used to calculate prepulse inhibition, startle responses, fear-potentiated startle, and shock reactivity. White-noise sound was produced by a high-frequency speaker located in the ceiling of the chamber. Background sound was maintained at a constant $65 \mathrm{~dB}$ level. Sound levels were measured in decibels (A scale) using a sound level reader (RadioShack). A calibration unit was used to ensure the integrity of the startle response readings (San Diego Instru-

A

C

$\mathbf{F}$

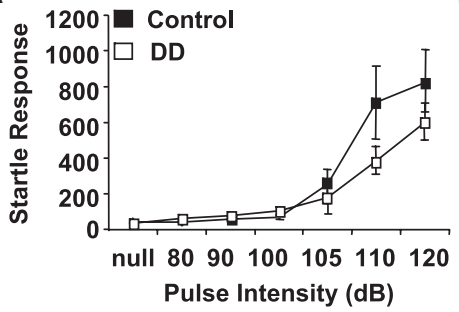

B
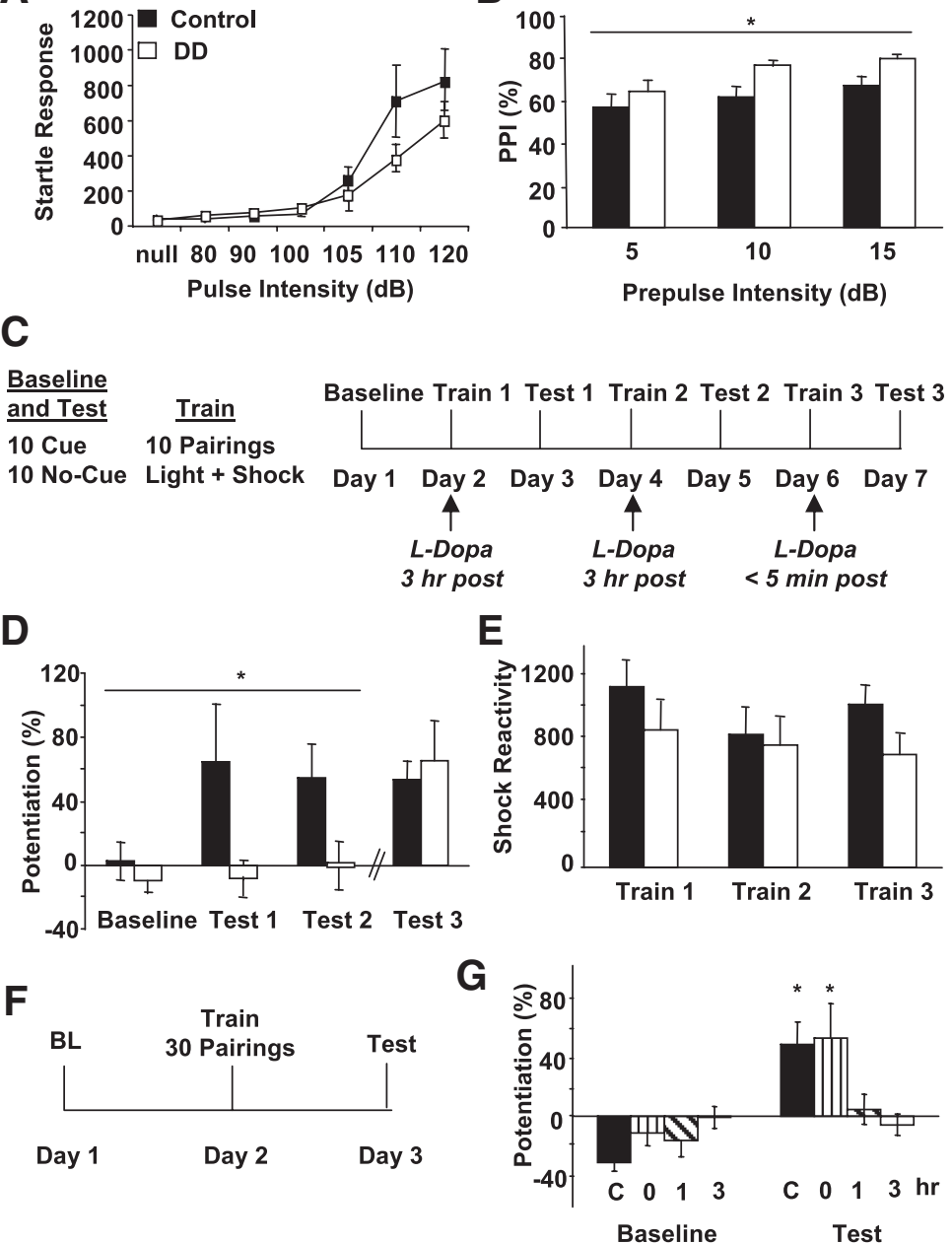

Figure 1. DA is critical for learning fear-potentiated startle. $A$, Acoustic startle response of control ( $n=10$; black squares) and (10 s light cue coterminating with the startle pulse) in pseudorandom order. On training days, mice received 10 pairings of the $10 \mathrm{~s}$ tiation on cue trials when compared with no-cue trials. D, DD mice ( $n=10$; white bars) given L-Dopa $3 \mathrm{~h}$ after training (Day 2, Day 4) failed to learn (Test 1, Test 2). However, when DD mice were injected immediately after training (Day 6), they displayed significant fear-potentiated startle (Test 3). ${ }^{*} p<0.05$, repeated-measures ANOVA. $E$, Measurements of shock reactivity during training sessions (control, $n=10$, black bars; DD, $n=10$, white bars). Responses are reported in arbitrary units. $F$, Schematic illustrating the $3 \mathrm{~d}$ fear-potentiated startle paradigm used to determine the critical time period in which DA is important. All 30 cue-shock pairings were given on 1 training day, and DD mice were treated with L-Dopa immediately, $1 \mathrm{~h}$, or $3 \mathrm{~h}$ posttraining. $G$, Only control ( $n=8$; solid black bars, C) and DD mice injected immediately after training ( $n=7$; vertical stripes, $0 \mathrm{~h}$ ) exhibited fear-potentiated startle on the test day. This level of fear-potentiated startle was significantly higher than that seen in the DD mice given L-Dopa $1 \mathrm{~h}$ ( $n=6$; diagonal stripes) or $3 \mathrm{~h}\left(n=6\right.$; white bars) after training. ${ }^{*} p<0.05$ when compared with baseline, Fisher's post hoc. All values reported are means \pm SEM.

ments). An $8 \mathrm{~W}$ light was mounted on the rear wall of the startle box for use as a cue.

Startle response curves. After a $5 \mathrm{~min}$ habituation period, animals were presented with a series of seven trials with escalating sound levels: from 80 to $120 \mathrm{~dB}$, with an intertrial interval (ITI) of $30 \mathrm{~s}$. This series was presented 10 times for a total of 70 trials. In all trials, except null trials in which there was no sound, the sound pulse was $40 \mathrm{~ms}$.

Prepulse inhibition. Animals were given a $10 \mathrm{~min}$ habituation period, after which subjects were presented with five $40 \mathrm{~ms}, 120 \mathrm{~dB}$, pulse-alone trials. Mice were then presented with 50 trials of a startle pulse-alone trial, one of three prepulse trials (5, 10, and $15 \mathrm{~dB}$ above background), or a null trial in which there was no acoustic stimulus. The ITI averaged $15 \mathrm{~s}$ 
(range, 5-25 s). A startle trial consisted of a $40 \mathrm{~ms}, 120 \mathrm{~dB}$ pulse of white noise. Prepulse trials consisted of a $20 \mathrm{~ms}$ duration prepulse of 70,75 , or $80 \mathrm{~dB}$ intensity, which preceded the $40 \mathrm{~ms}, 120 \mathrm{~dB}$ pulse by $100 \mathrm{~ms}$. Prepulse inhibition was calculated for each prepulse level using the following formula: $\%$ inhibition $=[$ (average startle response on prepulse trial/average startle response on pulse-alone trial) $\times 100]$. DD mice were tested in a DA-depleted state, $18-24 \mathrm{~h}$ after L-Dopa injection.

Fear-potentiated startle ( $7 \mathrm{~d}$ paradigm). On day 1 (baseline), after a 5 min habituation period, mice were given a pseudorandomly ordered series of 20 trials, split evenly between cue and no-cue conditions. For no-cue trials, animals were presented with a $40 \mathrm{~ms}, 105 \mathrm{~dB}$ acoustic pulse. For cue trials, the animals were presented with a $10 \mathrm{~s}$ light cue, which coterminated with a $40 \mathrm{~ms}, 105 \mathrm{~dB}$ pulse. The ITI averaged $120 \mathrm{~s}$ (range, $60-180 \mathrm{~s})$.

Training occurred on days 2, 4, and 6. After a 10 min habituation period, mice were given 10 presentations of the cue light, which coterminated with a $0.2 \mathrm{~mA}, 0.5 \mathrm{~s}$ footshock. The ITI averaged $120 \mathrm{~s}$ (range, $60-180 \mathrm{~s}$ ). The test sessions occurred on days 3,5 , and 7 and were identical to the baseline session described above. DD mice were in DAdepleted state, 18-24 h after their last L-Dopa injection, during baseline, training, and testing sessions. L-Dopa was injected after training sessions as indicated in figure legends.

The following formula was used to calculate fear-potentiated startle: $\%$ potentiation $=[($ average of responses on cue trials/average of responses on no-cue trials -1$) \times 100]$.

Fear-potentiated startle (3 d paradigm). Days 1 and 3 (baseline and test) of this paradigm were identical to those described for the $7 \mathrm{~d}$ fearpotentiated startle paradigm. On day 2 (training), mice received 30 pairings of the $10 \mathrm{~s}$ cue light with a $0.2 \mathrm{~mA}, 0.5 \mathrm{~s}$ footshock. The ITI mean was $120 \mathrm{~s}$ (range, 60-180 s). DD mice were DA-depleted during baseline, training, and testing.

Short-term memory. Baseline and test sessions were identical to those described for the $7 \mathrm{~d}$ paradigm. On day 2, after a 5 min habituation period, mice were given 30 pairings of a $10 \mathrm{~s}$ cue light, which coterminated with a $0.5 \mathrm{~s}, 0.2 \mathrm{~mA}$ footshock. The ITI averaged $120 \mathrm{~s}$ (range, 60-180). After training, the mice were placed into their home cages for $10 \mathrm{~min}$ before testing. Short-term memory was assessed by using the same formula used for fear-potentiated startle.

Shock sensitization. Responses to the no-cue condition during the short-term memory baseline and testing sessions were averaged for each animal, and the following formula was used to calculate shock sensitization: $\%$ sensitization $=[($ average startle response during testing/average startle response on baseline -1$) \times 100]$.

Cre recombinase-mediated restoration of Th gene function. Isoflurane (1.5-5\%) anesthetized mice were placed into a stereotaxic instrument (David Kopf Instruments). For restoration of Th gene function in the ventral tegmental area (VTA), recombinant adeno-associated virus (type 1) expressing Cre recombinase-green fluorescent fusion protein (AAV1Cre-GFP) (titered at $1.2 \times 10^{12}$ particles $/ \mathrm{ml}$ ) was injected bilaterally into the ventral midbrain (coordinates in $\mathrm{mm}$ : 3.5 posterior to bregma, 0.5 lateral to midline, 4.5 ventral to bregma; $0.5 \mu \mathrm{l} /$ hemisphere). For specific restoration of basolateral amygdala (BLA) DA, recombinant canine adenovirus (type 2) expressing Cre recombinase (CAV2-Cre) (titered at $2.1 \times 10^{12}$ particles $/ \mathrm{ml}$ ) was injected bilaterally (coordinates in $\mathrm{mm}: 1.5$ posterior to bregma, 3.25 lateral to midline, 5 ventral to bregma; 0.5 $\mu \mathrm{l} /$ hemisphere). Detailed descriptions of both viral vectors have been published previously (Hnasko et al., 2006; Zweifel et al., 2008). Viruses were injected over a $10 \mathrm{~min}$ period using a 32 gauge syringe needle (Hamilton) attached to a microinfusion pump (WPI).

Immunohistochemistry. After anesthesia with $50 \mathrm{mg} / \mathrm{ml}$ sodium pentobarbital $(0.2-0.3 \mathrm{ml} /$ animal $)$, mice were transcardially perfused with PBS, followed by $4 \%$ paraformaldehyde in PBS. Dissected brains were postfixed in $4 \%$ paraformaldehyde overnight, cryoprotected in $30 \%$ sucrose in PBS, and then quick frozen in isopentane. Free-floating coronal sections $(30 \mu \mathrm{m})$ were immunostained with either mouse anti-TH (1: 1000; Millipore Bioscience Research Reagents) or rabbit anti-TH (1:2000; Millipore Bioscience Research Reagents) antibodies. Immunofluorescence was achieved by using cyanine 2- or cyanine 3-conjugated IgG secondary antibodies (1:200; Jackson ImmunoResearch). Stained
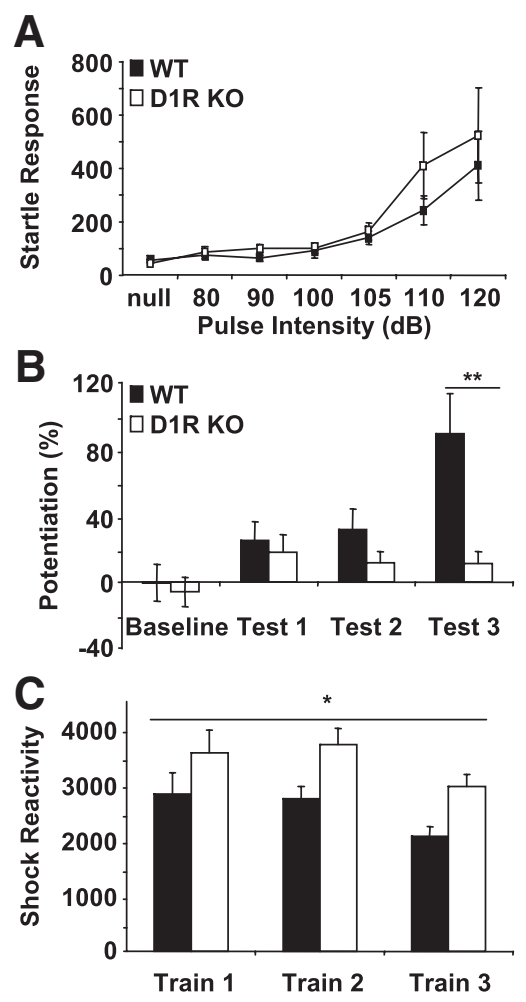

Figure 2. $\quad D_{1} R K O$ mice have significantly impaired learning. $A$, Acoustic startle response of $\mathrm{D}_{1} \mathrm{R}$ WT ( $n=9$; black squares) and KO ( $n=9$; white squares) mice. $\boldsymbol{B}$, Results of $7 \mathrm{~d}$ fearpotentiated startle paradigm with $D_{1} R$ mice. $D_{1} R$ WT mice ( $n=9$; solid black bars) but not $D_{1} R$ K0 mice ( $n=9$; white bars) displayed fear-potentiated startle by test day 3 . ${ }^{* *} p<0.01$, comparing KO with WT, Fisher's post hoc. $C$, Measurements of shock reactivity. $D_{1} R$ KO mice ( $n=9$; white bars) have higher responses to footshock than WT ( $n=9$; black bars). ${ }^{*} p<0.05$, repeated-measures ANOVA. All values reported are means $\pm S E M$. For startle responses and shock reactivity, numbers reported in arbitrary units.

sections were mounted on slides, coverslipped, and photographed with an upright bright-field microscope (Nikon).

Statistical analyses. Analyses performed included repeated-measures and one-way ANOVA, Fisher's post hoc, and Student's $t$ tests as noted in Results. Statistical analysis was performed using Statistica software (Statsoft).

\section{Results}

\section{DD mice have intact acoustic startle response and normal prepulse inhibition}

Fear-potentiated startle requires intact acoustic startle responses and sensorimotor gating. To determine whether the acoustic startle response is altered in the absence of DA, the responses of DA-depleted DD mice (18-24 h after L-Dopa) to multiple decibel levels of sound were measured and compared with controls (Fig. $1 A)$. Repeated-measures ANOVA showed no main effect of genotype and no significant interaction between genotype and sound level.

DA-depleted DD and control mice were also tested in a prepulse inhibition paradigm, which is commonly used to detect deficits in sensorimotor gating. Prepulse inhibition was enhanced in DD mice (Fig. 1B) (repeated-measures ANOVA; genotype, $F_{(1,18)}=5.37 ; p<0.05$; no significant genotype by prepulse level interaction was detected). These data indicate that DD mice do not have deficits in startle responses or decreases in sensorimotor gating mechanisms while in a DA-depleted state and validate their use in fear-potentiated startle experiments. 
Dopamine is necessary at a critical time for learning fear-potentiated startle

To determine whether DA is necessary for learning a cued-fear conditioning task, DD and control mice were subjected to a $7 \mathrm{~d}$ fear-potentiated startle paradigm (Fig. 1C). DD mice were trained and tested in a DA-depleted state. When tested $24 \mathrm{~h}$ after training, control mice exhibited fear-potentiated startle after a single training session that was not observed in DD mice (Fig. 1D) (repeated-measures ANOVA; genotype, $\left.F_{(1,18)}=7.4590 ; p<0.05\right)$. Even after an additional training session, DD mice failed to express fear-potentiated startle, whereas control mice continued to express robust learning. Interestingly, when given L-Dopa immediately after training on day 6, DD mice showed fear-potentiated startle that was significantly higher than baseline (one-way ANOVA, $F_{(1,18)}=9.1999 ; p<$ 0.01 ) and did not differ from control levels (Fig. 1D). Shock reactivity across training days for DD and control mice were not significantly different between genotypes on any training day, indicating that the learning deficit in DD mice was not attributable to an inability to sense the footshock (Fig. 1E).

To characterize the critical time window for DA action, an additional study varied the time of L-Dopa administration. DD and control mice were given a training session consisting of 30 light-shock pairings (Fig. $1 F$ ) and then injected with L-Dopa immediately, $1 \mathrm{~h}$, or $3 \mathrm{~h}$ after training, and they were tested $24 \mathrm{~h}$ later. DD mice injected immediately after training expressed robust fear-potentiated startle on the test day, similar to that of controls, whereas the DD mice injected with L-Dopa 1 or $3 \mathrm{~h}$ after training showed no learning (Fig. 1G) (repeated-measures ANOVA; treatment $\times$ session, $F_{(3,23)}=$ 5.1032; $p<0.01)$. These data indicate that DA is necessary within a finite time period for learning in a fear-potentiated startle paradigm. However, DA is not necessary for the expression of cued-fear memory because DD animals were always tested in the absence of DA. Additionally, the absence of DA does not impair shock reactivity.

\section{$D_{1} R$ is necessary for} fear-potentiated startle

To explore which DA receptors are necessary for fear-potentiated startle, we first analyzed $\mathrm{D}_{1} \mathrm{R}$ KO mice. $\mathrm{D}_{1} \mathrm{R}$ KO and control, WT mice were tested at multiple levels of startle-pulse intensity, as described for DD mice (Fig. 2 A). There was no significant difference between $\mathrm{D}_{1} \mathrm{R}$ KO and WT mice at any sound level tested, indicating that $\mathrm{D}_{1} \mathrm{R} \mathrm{KO}$ mice have an intact acoustic startle re-
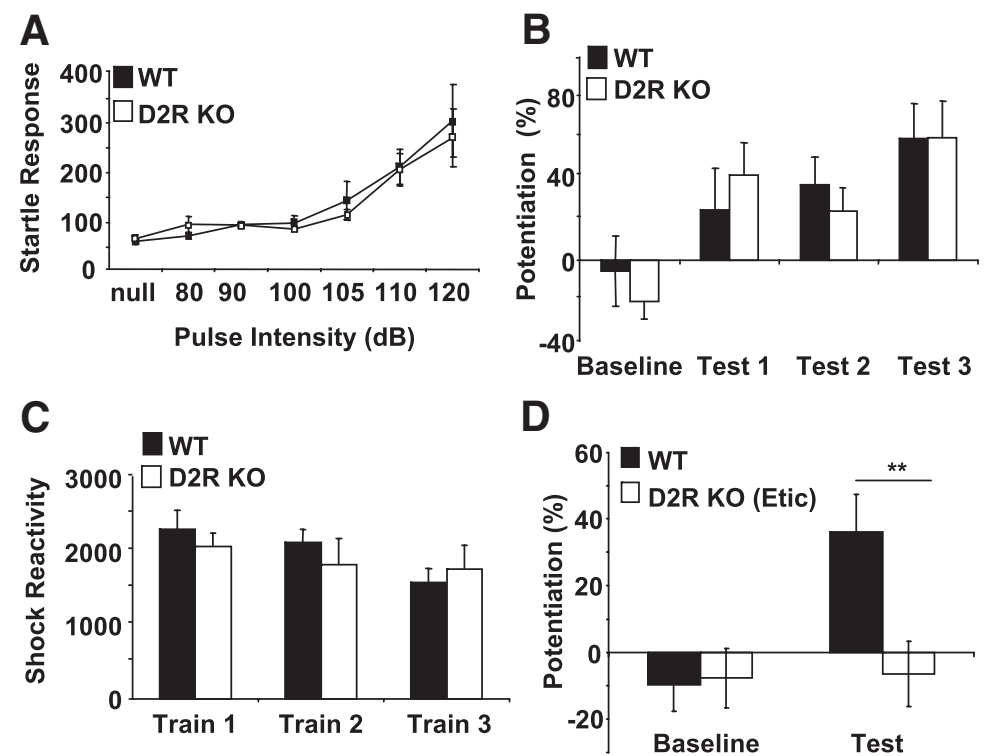

Figure 3. $\mathrm{D}_{2} \mathrm{RKO}$ mice have intact fear-potentiated startle. $\boldsymbol{A}$, Acoustic startle response of $\mathrm{D}_{2} \mathrm{RWT}$ ( $n=8$; black squares) and K0 ( $n=8$; white squares) mice. $\boldsymbol{B}$, Results of $7 \mathrm{~d}$ fear-potentiated startle paradigm with $\mathrm{D}_{2} \mathrm{R}$ mice. Both WT ( $n=8$; black bars) and KO ( $n=8$; white bars) mice exhibited significant levels of fear-potentiated startle. $C$, Measurements of shock reactivity during training (WT, $n=8$, black bars; K0, $n=8$, white bars). $\boldsymbol{D}$, WT and $\mathrm{D}_{2} \mathrm{R}$ KO mice ( $n=11$ each) were subjected to the $3 \mathrm{~d}$ fear-potentiated startle paradigm. $D_{2} R$ KO mice were administered eticlopride $(0.5 \mathrm{mg} / \mathrm{kg})$ before training and failed to express fear-potentiated startle on testing. ${ }^{* *} p<0.01$, KO versus WT, Fisher's post hoc. All values reported are mean \pm SEM. For startle responses and shock reactivity, responses are reported in arbitrary units.
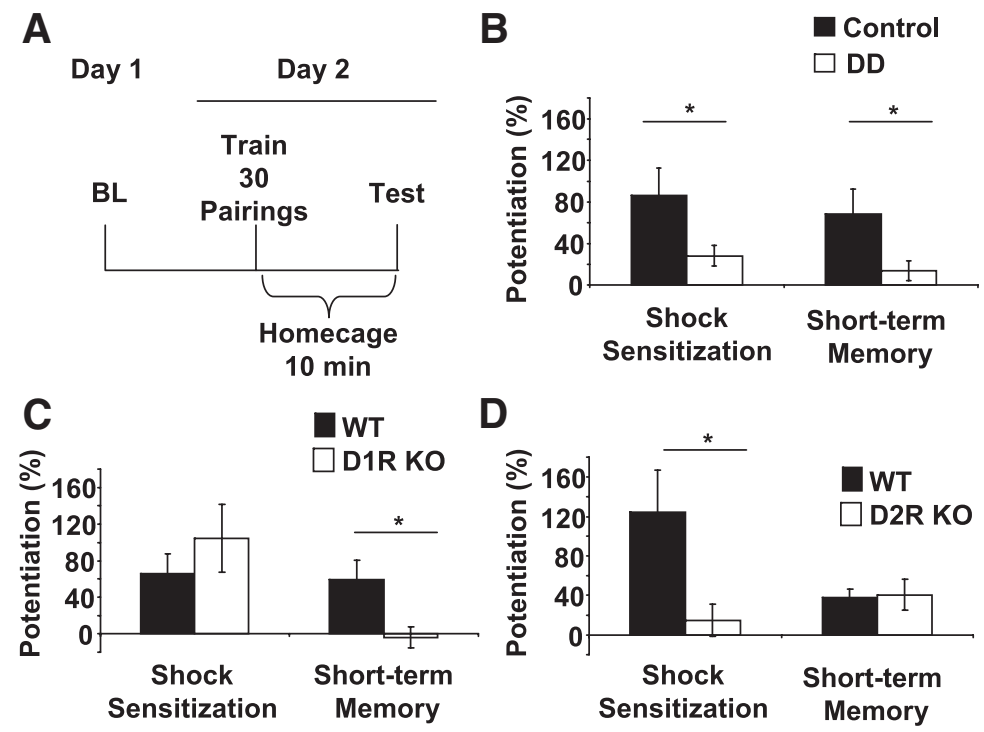

Figure 4. Short-term memory and shock sensitization depend on DA. A, Design of the behavioral paradigm. On day 1, baseline startle responses were obtained. 0 n day 2, mice received all 30 cue-shock pairings and were then put back in their home cage for 10 min before testing. $\boldsymbol{B}$, Control mice ( $n=10$; black bars) have significantly greater shock sensitization and fear-potentiated startle when compared with DD ( $n=10$; white bars). ${ }^{*} p<0.05$, Student's $t$ test. C, WT ( $n=7$; black bars) and D, R KO ( $n=7$; white bars) mice have intact shock sensitization. Only WT have fear-potentiated startle during the short-term memory test. ${ }^{*} p<$ 0.05 , K0 versus WT, Student's $t$ test. $\boldsymbol{D}$, WT ( $n=8$; black bars) mice have significantly greater shock sensitization than $D_{2}$ R KO $(n=$ 8 ; white bars). Levels of fear-potentiated are similar between WT and $D_{2} R$ KO mice. ${ }^{*} p<0.05$, K0 versus WT, Student's $t$ test. All values reported are means \pm SEM.

sponse. In agreement with previous studies (Ralph-Williams et al., 2002), we have observed intact prepulse inhibition in $\mathrm{D}_{1} \mathrm{R} \mathrm{KO}$ mice (data not shown). When tested in the $7 \mathrm{~d}$ fear-potentiated startle paradigm, $\mathrm{D}_{1} \mathrm{R} \mathrm{KO}$ mice failed to express learning on any of the test days (Fig. $2 B$ ) (repeated-measures ANOVA; genotype $\times$ test day, $\left.F_{(3,48)}=6.28 ; p<0.01\right)$, whereas WT mice had 


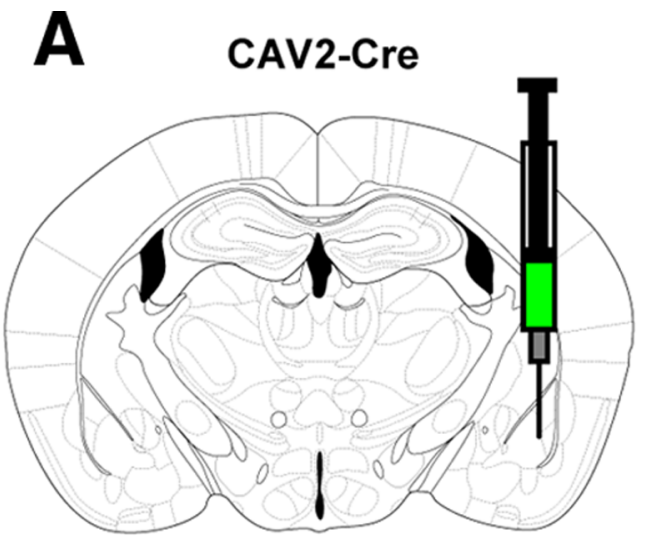

B

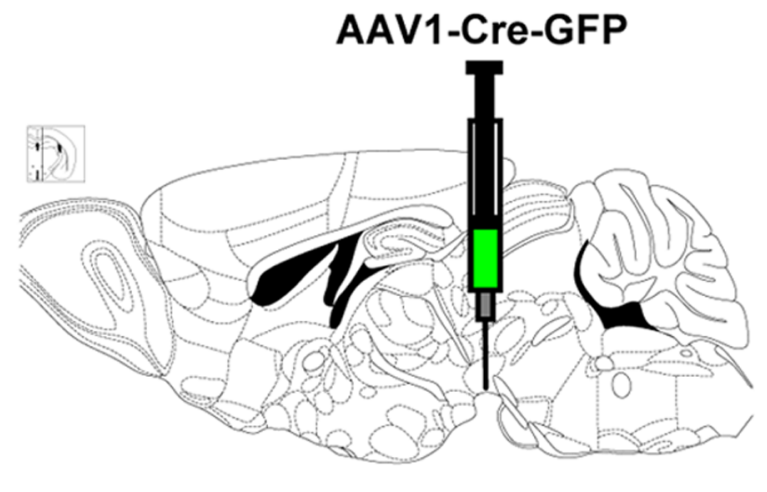

\section{Control}
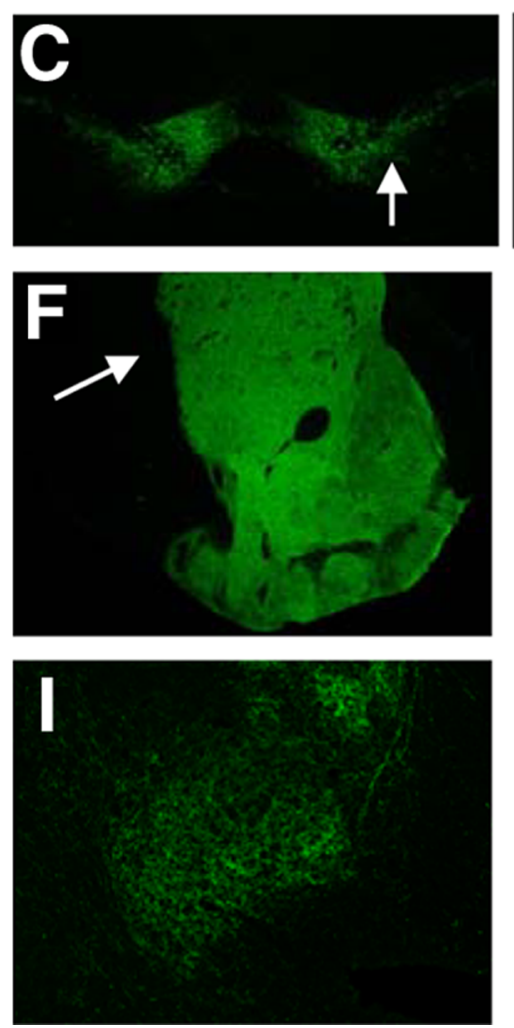

BLA-Rescue
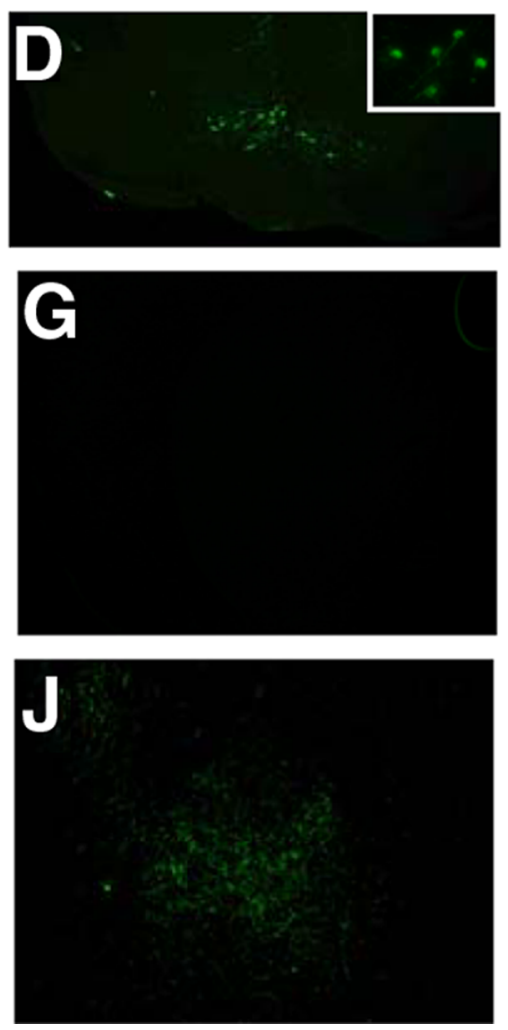

VTA-Rescue
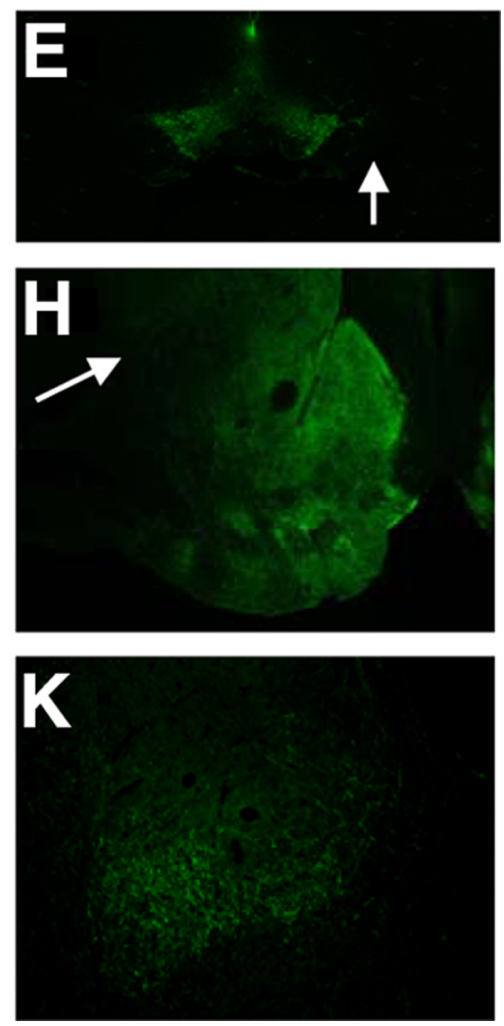

Figure 5. Region-specific restoration of endogenous TH expression in DD mice. $A$, Schematic illustrating injection coordinates for BLA rescue experiments. DD $(n=7)$ and control $(n=7)$ mice were injected bilaterally into the BLA with CAV2-Cre vectors ( $0.5 \mu \mathrm{l} /$ hemisphere). B, Schematic illustrating injection coordinates for VTA rescue experiments. AAV1-Cre-GFP was injected bilaterally $(0.5 \mu \mathrm{l} /$ hemisphere) into the VTA of DD $(n=7)$ and control $(n=10)$ mice. Figures adapted from Paxinos and Franklin (2001). C $E$, Comparison of TH staining in coronal slice (4X magnification) showing ventral midbrain of virus-injected WT control, BLA-injected DD, and VTA-injected DD. C, TH immunohistochemistry in control midbrain demonstrates the presence of DA neurons in the VTA and substantia nigra pars compacta (indicated by arrow). $\boldsymbol{D}$, BLA-rescued DD mice had a small number of TH-positive neurons in the VTA. Inset is a $40 \times$ magnification of the boxed region, showing TH expression in the soma and processes. $\boldsymbol{E}$, VTA-rescued DD mice had TH expression predominately in the VTA. Note absence of TH staining in substantia nigra pars compacta (indicated by arrow). $\boldsymbol{F}-\boldsymbol{H}$, Coronal section (4× magnification) from WT virus-injected control, BLA-rescued, and VTA-rescued DD mice, showing TH expression in dorsal striatum and nucleus accumbens. $\boldsymbol{F}$, WT virus-injected controls have TH expression throughout the entirety of the dorsal (indicated by arrow) and ventral striatum. $\mathbf{G}$, There is no TH expression detected in the striatum of BLA-rescued DD mice. $\boldsymbol{H}$, VTA-rescued DD mice have TH expression in the nucleus accumbens, with only a paucity of staining in the dorsal striatum (indicated by arrow). $\boldsymbol{I}-\boldsymbol{K}$, Coronal section (10 $\times$ magnification) showing TH expression in the BLA of virus-injected WT control, BLA-rescued, and VTA-rescued DD mice.

significant fear-potentiated startle on test days 2 and 3 ( $p<0.05$ and $p<0.01$, control baseline vs tests 2 and 3, respectively, Fisher's post hoc). $\mathrm{D}_{1} \mathrm{R}$ KO mice had greater shock reactivity than WT on all three training days (Fig. 2C) (repeated-measures ANOVA; genotype, $F_{(1,16)}=10.18 ; p<0.01$; no significant genotype $\times$ training day was observed). Thus, although $\mathrm{D}_{1} \mathrm{R} \mathrm{KO}$ mice have elevated responses to footshock compared with WT mice, they have significantly impaired fear-potentiated startle, even after $3 \mathrm{~d}$ of training. These data indicate a learning impairment in $\mathrm{D}_{1} \mathrm{R} \mathrm{KO}$ animals and implicate the $\mathrm{D}_{1} \mathrm{R}$ in mediating the effects of $\mathrm{DA}$ in cue-dependent fear conditioning.

Fear-potentiated startle is intact in $\mathrm{D}_{2} \mathrm{R} K \mathrm{KO}$ mice but requires other $\mathrm{D}_{2}$-like receptors

To explore whether $\mathrm{D}_{2}$-like receptors are necessary for fearpotentiated startle, $\mathrm{D}_{2} \mathrm{R} \mathrm{KO}$ and WT mice were subjected to the 
startle response and fear-potentiated startle tests. WT and $\mathrm{D}_{2} \mathrm{R}$ $\mathrm{KO}$ mice have equivalent startle responses at all decibel levels tested, indicating that $\mathrm{D}_{2} \mathrm{R}$ KO mice have an intact acoustic startle response (Fig. $3 A$ ). We have also observed that $\mathrm{D}_{2} \mathrm{R}$ KO mice have intact prepulse inhibition (data not shown), consistent with previous results (Ralph-Williams et al., 2002). When tested in the $7 \mathrm{~d}$ fear-potentiated startle paradigm, both $\mathrm{WT}$ and $\mathrm{D}_{2} \mathrm{R} \mathrm{KO}$ mice displayed fear-potentiated startle at equivalent levels on all three test days (Fig. 3B), and shock reactivity was not different between groups (Fig. $3 C$ ). These data indicate that $\mathrm{D}_{2}$ Rs are not necessary for learning fear-potentiated startle.

Previous studies have shown that administration of $\mathrm{D}_{2}$-like antagonists, either systemically or directly into the amygdala, impairs conditioned fear (Guarraci et al., 2000; Greba et al., 2001; Ponnusamy et al., 2005). To explore the discrepancy between their results and ours, $\mathrm{D}_{2} \mathrm{R} \mathrm{KO}$ mice were administered the $\mathrm{D}_{2} \mathrm{R}$ like antagonist eticlopride $(0.5 \mathrm{mg} / \mathrm{kg}$, i.p. ) before training in the $3 \mathrm{~d}$ fear-potentiated startle paradigm. When tested $24 \mathrm{~h}$ after training, vehicle-injected WT mice displayed robust fearpotentiated startle, whereas eticlopride-injected $\mathrm{D}_{2} \mathrm{R} \mathrm{KO}$ mice did not manifest learning (Fig. $3 D$ ) (repeated-measures ANOVA; genotype $\times$ day, $\left.F_{(1,20)}=7.5698 ; p<0.05\right)$. These results suggest that, in addition to the $\mathrm{D}_{1} \mathrm{R}$, a member of the $\mathrm{D}_{2}$-like family of $\mathrm{DA}$ receptors, but not the $\mathrm{D}_{2} \mathrm{R}$, is essential for fear-potentiated startle.

\section{Short-term memory is impaired in DD and $D_{1} R$ KO mice}

$\mathrm{DA}$ is required within $1 \mathrm{~h}$ after training to learn fear-potentiated startle. In these experiments, long-term memory for fearpotentiated startle was assayed $24 \mathrm{~h}$ after training. We set out to test whether DA is also required for short-term memory. DD animals and controls were subjected to a $2 \mathrm{~d}$ paradigm that tested short-term memory $10 \mathrm{~min}$ after training (Fig. $4 A$ ). On the test day, shock sensitization and short-term memory were assessed. Short-term memory was defined as cue-dependent increases in startle responses, whereas shock sensitization is a contextdependent potentiation of the acoustic startle response after footshock that is independent of cue (McNish et al., 1997; Richardson, 2000; Risbrough et al., 2009). DD mice had significantly less shock sensitization than controls (Fig. $4 B)(p<0.05$, Student's $t$ test). Similarly, control mice demonstrated robust shortterm memory that was absent in DD mice (Fig. $4 B)(p<0.05$, DD vs control, Student's $t$ test). These data suggest that DA is required for short-term and long-term memory of fearpotentiated startle. Furthermore, DA is necessary for contextdependent fear learning, as assayed by shock sensitization. These data also reinforce the previous conclusion that DA is required in a critical period for the stabilization of the fear conditioning memory trace.

To explore which receptor subtypes mediate the role of DA in short-term memory and shock sensitization, $\mathrm{D}_{1} \mathrm{R}$ and $\mathrm{D}_{2} \mathrm{R}$ KO mice were tested in the same paradigm as DD mice. $D_{1} R$ KO mice had significantly lower levels of short-term memory than WT mice (Fig. $4 C)$ ( $p<0.05$, Student's $t$ test); however, there was no significant difference between levels of shock sensitization in $D_{1} R$ $\mathrm{KO}$ and control mice, indicating that context-dependent learning was intact. $\mathrm{D}_{2} \mathrm{R} K \mathrm{KO}$ mice had significantly lower levels of shock sensitization than WT (Fig. 4D) ( $p<0.05$, Student's $t$ test), yet there was no significant difference between WT and $\mathrm{KO}$ mice levels of short-term memory. These findings indicate that the role of DA in cue-dependent short-term memory is mediated by the $\mathrm{D}_{1} \mathrm{R}$, whereas context-dependent shock sensitization relies critically on the $\mathrm{D}_{2} \mathrm{R}$.

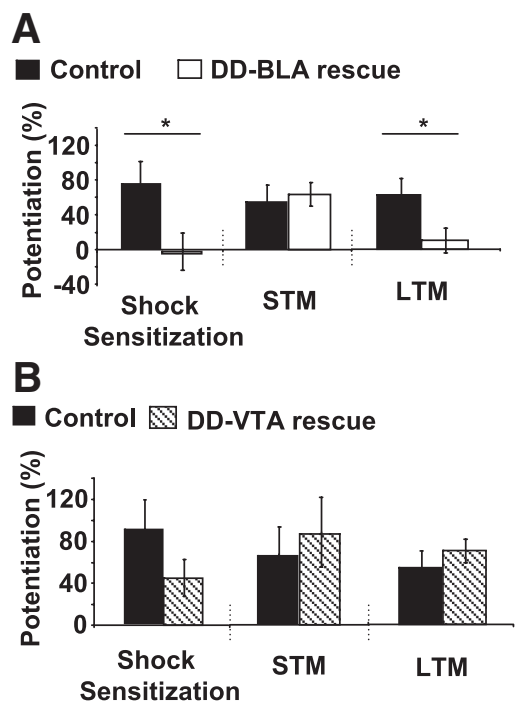

Figure 6. BLA-rescued DD mice have restored short-term memory, whereas VTA-rescued DD mice have fully restored learning. $A$, Virus-injected WT control $(n=7)$ and BLA-rescued DD $(n=7)$ mice were subjected to the $3 \mathrm{~d}$ fear-potentiated startle paradigm. Left, Shock sensitization is significantly lower in BLA-rescued mice. Middle, Short-term memory (STM) was restored to control levels in BLA-rescued mice. Right, Long-term memory (LTM), assessed $24 \mathrm{~h}$ after training, is absent in BLA-rescued mice. $\boldsymbol{B}$, Results from WT control $(n=10)$ and VTArescued DD $(n=7)$ mice in the $3 \mathrm{~d}$ fear-potentiated startle paradigm. Left, Shock sensitization in VTA-rescued DD mice was not significantly different from control. Middle and Right, Levels of STM and LTM memory were the same as control in VTA-rescue mice. ${ }^{*} p<0.05$, rescue versus control, Student's $t$ test. All values reported are means \pm SEM.

\section{Restoration of DA to the basolateral amygdala is sufficient to allow short-term memory}

The basolateral amygdala is critical for the acquisition of cuedependent fear memory (Maren, 2003; Maren and Quirk, 2004; Sigurdsson et al., 2007). Furthermore, there is evidence suggesting an important role for DA in facilitating basolateral amygdala function (Rosenkranz and Grace, 2002; Bissière et al., 2003; Marowsky et al., 2005). To explore whether DA in the basolateral amygdala is required for fear-potentiated startle, DD and control mice were injected bilaterally with a CAV2-Cre vector into the basolateral amygdala (Fig. 5A). This vector is retrogradely transported from the site of injection to DA neurons in which it restores Th gene activity (Hnasko et al., 2006). Immunohistochemistry revealed that TH was present in the basolateral amygdala of CAV2-Cre-injected DD mice (Fig. 5J) but absent in the dorsal striatum and nucleus accumbens (Fig. 5G). TH was primarily restored to a small number of neurons in the caudal portions of the ventral tegmental area (Fig. 5D). There were typically fewer than $10 \mathrm{TH}$-positive cells per $30 \mu \mathrm{m}$ section in the injected DD mice, which is consistent with the small numbers of amygdala-projecting DA neurons reported in the literature (Ford et al., 2006; Lammel et al., 2008; Margolis et al., 2008).

Basolateral amygdala-injected mice were subjected to a $3 \mathrm{~d}$ fear-potentiated startle paradigm. Short-term memory and shock sensitization were assessed $10 \mathrm{~min}$ after training, and longterm memory for fear-potentiated startle was assessed $24 \mathrm{~h}$ after training (Fig. 6A). Interestingly, only short-term memory was restored in basolateral amygdala-injected DD mice. Levels of short-term memory were the same as controls, yet levels of longterm memory ( $p<0.05$, Student's $t$ test) and shock sensitization ( $p<0.05$, Student's $t$ test) were significantly lower than controls. During training, levels of shock reactivity were the same between groups (control, $1613 \pm 333$ vs BLA-rescued DD, $1758 \pm 260$ ). 
These data suggest that DA projections to the basolateral amygdala, emanating mainly from the caudal aspect of the ventral tegmental area, are sufficient for short-term acquisition of cuedfear memory, yet DA projections to other cortical or limbic brain areas are likely essential for contextual learning and long-term stabilization of the fear memory trace.

\section{Restoration of TH to ventral tegmental area DA neurons is sufficient for learning}

There are two major DA circuits emanating from the ventral midbrain: the mesostriatal circuit, stemming primarily from the substantia nigra pars compacta, and the mesocorticolimbic circuit, originating primarily from the ventral tegmental area. The mesocorticolimbic circuit projects widely to brain nuclei known to be important for cue-dependent fear conditioning, including the basolateral amygdala (Björklund and Dunnett, 2007; Lammel et al., 2008). To explore whether more complete restoration of mesocorticolimbic DA is required for long-term memory and shock sensitization, DD and control mice were injected bilaterally with an $A A V 1-C r e-G F P$ vector into the ventral tegmental area to specifically activate the endogenous Th gene (Fig. $5 B$ ). Immunohistochemistry was used to detect which DA neurons and which targets had restored TH expression. TH staining is absent in nonrescued DD mice (Hnasko et al., 2006). Immunohistochemistry revealed that restoration of $\mathrm{TH}$ in ventral tegmental area-injected DD mice was highly specific to the ventral tegmental area and its targets (Fig. $5 E, H, K$ ). There was a paucity of TH staining in the dorsal striatum, a major target of DA neurons emanating from the substantia nigra pars compacta (Fig. $5 \mathrm{H}$ ), whereas the nucleus accumbens and basolateral amygdala had robust $\mathrm{TH}$ expression (Fig. $5 H, K$ ).

Ventral tegmental area-injected mice were subjected to the same $3 \mathrm{~d}$ fear-potentiated startle paradigm as basolateral amygdala-injected mice (Fig. 6B). Shock sensitization, shortterm memory, and long-term memory were restored to control levels in the ventral tegmental area-injected DD mice. Shock reactivity during training was the same between groups (control, $1653 \pm 268$ vs VTA-rescued DD, $1602 \pm 198$ ). These data suggest that DA projections from the ventral tegmental area are sufficient for the formation of short-term and long-term cued-fear memory as well as context-dependent shock sensitization.

\section{Discussion}

These results demonstrate that DA is required for cued-fear conditioning as measured by fear-potentiated startle. DD mice failed to exhibit fear-potentiated startle unless DA was restored immediately after training. DD mice also have impaired short-term memory and shock sensitization. Importantly, prepulse inhibition was not lower in DA-depleted DD mice, indicating that sensorimotor gating is not diminished in the absence of DA. Previous research has shown that psychostimulants that enhance DA transmission can lower prepulse inhibition (Schwarzkopf et al., 1992; Bubser and Koch, 1994; Ralph et al., 1999; Swerdlow et al., 2006; Doherty et al., 2008), and others have demonstrated that pharmacological inhibition of dopamine receptors enhances prepulse inhibition (Schwarzkopf et al., 1993; Depoortere et al., 1997). Consistent with these findings, DD mice had a small but significant increase in prepulse inhibition over control mice. Previous studies have also demonstrated that pharmacological inhibition of DA receptors can reduce the acoustic startle response (Davis and Aghajanian, 1976; Schwarzkopf et al., 1993). Dopamine-depleted DD mice did not have significantly altered acoustic startle responses; however, there was a trend to- ward reduced responses compared with controls, especially at high stimulus intensities, consistent with previous reports (Schwarzkopf et al., 1993).

The data presented here clearly demonstrate that DA is not important for the retrieval or expression of cue-dependent fear memory because DD mice do not require DA during the test session to express fear-potentiated startle that was previously acquired by injecting L-Dopa immediately after training. Furthermore, our experiments argue against DA being required for the initial stimulus processing during training because DD mice were dopamine-depleted during all training sessions. Instead, our data suggest that DA is necessary for the early stabilization of the memory trace because DD mice do not express short-term memory, and long-term memory is only seen when L-Dopa is given immediately, but not $1 \mathrm{~h}$, after training. Presumably, injecting DD mice with L-Dopa immediately after training stabilizes the memory trace, allowing it to enter a long-term form. Aversive stimuli cause prolonged rises in DA levels within brain regions crucial for fear-conditioning that would allow for such stabilization of fear memory (Abercrombie et al., 1989; Kalivas and Duffy, 1995; Doherty and Gratton, 1997; Inglis and Moghaddam, 1999). Consistent with our data, others have shown that post-training manipulations of DA function alter fear-related memory (Bernaerts and Tirelli, 2003; LaLumiere et al., 2004, 2005).

Our findings indicate that multiple DA receptor subtypes are necessary for fear-potentiated startle. $\mathrm{D}_{1} \mathrm{R} \mathrm{KO}$ mice lack shortterm and long-term memory for fear-potentiated startle, suggesting a crucial role for this receptor subtype in mediating the effects of DA in cue-dependent fear learning. Interestingly, contextdependent fear learning was intact in $\mathrm{D}_{1} \mathrm{R} \mathrm{KO}$ mice. These data corroborate other studies showing that $\mathrm{D}_{1} \mathrm{R}$-like antagonists attenuate cue-conditioned fear learning without affecting shock sensitization and demonstrate that the pharmacological manipulations in those experiments were specific to the $D_{1} R$ (Lamont and Kokkinidis, 1998; Guarraci et al., 1999). These data are also consistent with studies demonstrating a critical role for the $D_{1} R$ in other cue-dependent learning paradigms (Smith et al., 1998; Eyny and Horvitz, 2003).

$\mathrm{D}_{2} \mathrm{R} \mathrm{KO}$ had intact fear-potentiated startle yet lacked shock sensitization. Greba et al. (2001) have shown that intraamygdalar antagonism of $\mathrm{D}_{2} \mathrm{R}$ led to an impairment of shock sensitization and fear-potentiated startle without affecting baseline startle or responses to footshock. Activation of $\mathrm{D}_{2} \mathrm{R}$ leads to induction of long-term potentiation in the BLA, which presumably would be vital for fear-potentiated startle memory (Bissière et al., 2003). Our data demonstrate that $D_{2} R s$ are not necessary for cue-dependent fear learning but rather that this DA receptor subtype is important for context-dependent shock sensitization. Injecting $\mathrm{D}_{2} \mathrm{R} \mathrm{KO}$ mice systemically with the $\mathrm{D}_{2}$-like antagonist eticlopride before training prevented fear-potentiated startle; therefore, it is probable that other $\mathrm{D}_{2} \mathrm{R}$-like receptors, which are also inhibited by eticlopride, are critical in fear-potentiated startle (Sigala et al., 1997; Bernaerts and Tirelli, 2003; Laviolette et al., 2005; Swant and Wagner, 2006). Thus, impairments in cuedependent learning caused by $\mathrm{D}_{2}$-like antagonists in previous studies may be attributed to these drugs inhibiting other members of the $\mathrm{D}_{2} \mathrm{R}$ family.

The selective restoration of endogenous TH specifically to the ventral tegmental area led to a restoration of learning in DD mice. Immunohistochemistry indicated that $\mathrm{TH}$ was restored to important limbic nuclei, such as the nucleus accumbens and basolateral amygdala, but not to the dorsal striatum. Furthermore, there were very few neurons positive for TH in the substan- 
tia nigra pars compacta. These data indicate that DA from ventral tegmental area neurons is important for cued- and contextualfear conditioning.

Mice with selective restoration of DA to the basolateral amygdala expressed short-term memory but not long-term memory or shock sensitization. Previous studies have shown that DA facilitates amygdala function via alterations in GABAergic inhibitory tone, and this effect is mediated by either the $D_{1} R$ or the $D_{2} R$ (Bissière et al., 2003; Kröner et al., 2005; Marowsky et al., 2005). The data presented here demonstrate that DA in the basolateral amygdala is critical for the acquisition of short-term memory for fear-potentiated startle yet is not sufficient for the long-term stability of the memory. Restoration of short-term memory is mediated by a small number of basolateral amygdala-projecting DA neurons emanating from the ventral tegmental area. More widespread restoration of endogenous TH in ventral tegmental area-rescued DD mice led to intact short-term and long-term memory; therefore, restoration of $\mathrm{TH}$ to other mesocorticolimbic circuits is likely required to establish long-term memory for fear-potentiated startle. Previous studies suggest that the nucleus accumbens and prefrontal cortex may also be important targets of DA during fear conditioning (Kalivas and Duffy, 1995; Murphy et al., 2000; Pezze et al., 2003; LaLumiere et al., 2005; Laviolette et al., 2005; Floresco and Tse, 2007). Therefore, it is possible that DA signaling in either the nucleus accumbens or prefrontal cortex is required for the formation of long-term memory.

In summary, our study used a combination of genetic mouse models, pharmacology, and region-specific rescue of function to demonstrate that DA is required for fear-potentiated startle, a cue-dependent fear conditioning task. These findings emphasize an important role for this neurotransmitter outside of reward processing. Furthermore, our study indicates a need for DA acting on multiple DA receptors concurrently in multiple brain regions for cue-dependent fear conditioning. Recent studies have revealed that ventral tegmental area DA neurons vary significantly in their molecular and physiological properties according to target location (Ford et al., 2006; Margolis et al., 2006, 2008; Björklund and Dunnett, 2007; Lammel et al., 2008). The experiments we performed in which the $T h$ gene was selectively reactivated in DA neurons projecting to the basolateral amygdala reveal that they are a small, select population of ventral tegmental area neurons rather than collaterals of DA neurons projecting to other brain regions. Our data, combined with studies demonstrating the heterogeneity of DA neuron populations, emphasize the need to understand the role of each of these discrete DA circuits. Expanding knowledge of the many behavioral and physiological functions of DA to include fear-related learning may lead to a better understanding of prevalent fear-related disorders, such as posttraumatic stress disorder, obsessivecompulsive disorder, and generalized anxiety disorder.

\section{References}

Abercrombie ED, Keefe KA, DiFrischia DS, Zigmond MJ (1989) Differential effect of stress on in vivo dopamine release in striatum, nucleus accumbens, and medial frontal cortex. J Neurochem 52:1655-1658.

Bernaerts P, Tirelli E (2003) Facilitatory effect of the dopamine D4 receptor agonist PD168,077 on memory consolidation of an inhibitory avoidance learned response in C57BL/6J mice. Behav Brain Res 142:41-52.

Bissière S, Humeau Y, Lüthi A (2003) Dopamine gates LTP induction in lateral amygdala by suppressing feedforward inhibition. Nat Neurosci 6:587-592.

Björklund A, Dunnett SB (2007) Dopamine neuron systems in the brain: an update. Trends Neurosci 30:194-202.

Bubser M, Koch M (1994) Prepulse inhibition of the acoustic startle re- sponse of rats is reduced by 6-hydroxydopamine lesions of the medial prefrontal cortex. Psychopharmacology (Berl) 113:487-492.

Davis M, Aghajanian GK (1976) Effects of apomorphine and haloperidol on the acoustic startle response in rats. Psychopharmacology (Berl) 47:217-223.

de Oliveira AR, Reimer AE, Brandão ML (2006) Dopamine D2 receptor mechanisms in the expression of conditioned fear. Pharmacol Biochem Behav 84:102-111.

Depoortere R, Perrault G, Sanger DJ (1997) Potentiation of prepulse inhibition of the startle reflex in rats: pharmacological evaluation of the procedure as a model for detecting antipsychotic activity. Psychopharmacology (Berl) 132:366-374.

Doherty MD, Gratton A (1997) NMDA receptors in nucleus accumbens modulate stress-induced dopamine release in nucleus accumbens and ventral tegmental area. Synapse 26:225-234.

Doherty JM, Masten VL, Powell SB, Ralph RJ, Klamer D, Low MJ, Geyer MA (2008) Contributions of dopamine D1, D2, and D3 receptor subtypes to the disruptive effects of cocaine on prepulse inhibition in mice. Neuropsychopharmacology 33:2648-2656.

Drago J, Gerfen CR, Lachowicz JE, Steiner H, Hollon TR, Love PE, Ooi GT, Grinberg A, Lee EJ, Huang SP, et al (1994) Altered striatal function in a mutant mouse lacking D1A dopamine receptors. Proc Natl Acad Sci U S A 91:12564-12568.

Eyny YS, Horvitz JC (2003) Opposing roles of $\mathrm{D}_{1}$ and $\mathrm{D}_{2}$ receptors in appetitive conditioning. J Neurosci 23:1584-1587.

Floresco SB, Tse MT (2007) Dopaminergic regulation of inhibitory and excitatory transmission in the basolateral amygdala-prefrontal cortical pathway. J Neurosci 27:2045-2057.

Ford CP, Mark GP, Williams JT (2006) Properties and opioid inhibition of mesolimbic dopamine neurons vary according to target location. J Neurosci 26:2788-2797.

Greba Q, Kokkinidis L (2000) Peripheral and intraamygdalar administration of the dopamine D1 receptor antagonist SCH 23390 blocks fearpotentiated startle but not shock reactivity or the shock sensitization of acoustic startle. Behav Neurosci 114:262-272.

Greba Q, Munro LJ, Kokkinidis L (2000) The involvement of ventral tegmental area cholinergic muscarinic receptors in classically conditioned fear expression as measured with fear-potentiated startle. Brain Res 870:135-141.

Greba Q, Gifkins A, Kokkinidis L (2001) Inhibition of amygdaloid dopamine D2 receptors impairs emotional learning measured with fearpotentiated startle. Brain Res 899:218-226.

Guarraci FA, Kapp BS (1999) An electrophysiological characterization of ventral tegmental area dopaminergic neurons during differential pavlovian fear conditioning in the awake rabbit. Behav Brain Res 99:169-179.

Guarraci FA, Frohardt RJ, Kapp BS (1999) Amygdaloid D1 dopamine receptor involvement in Pavlovian fear conditioning. Brain Res 827:28-40.

Guarraci FA, Frohardt RJ, Falls WA, Kapp BS (2000) The effects of intraamygdaloid infusions of a D2 dopamine receptor antagonist on Pavlovian fear conditioning. Behav Neurosci 114:647-651.

Hnasko TS, Perez FA, Scouras AD, Stoll EA, Gale SD, Luquet S, Phillips PE, Kremer EJ, Palmiter RD (2006) Cre recombinase-mediated restoration of nigrostriatal dopamine in dopamine-deficient mice reverses hypophagia and bradykinesia. Proc Natl Acad Sci U S A 103:8858-8863.

Horvitz JC (2000) Mesolimbocortical and nigrostriatal dopamine responses to salient non-reward events. Neuroscience 96:651-656.

Inglis FM, Moghaddam B (1999) Dopaminergic innervation of the amygdala is highly responsive to stress. J Neurochem 72:1088-1094.

Inoue T, Izumi T, Maki Y, Muraki I, Koyama T (2000) Effect of the dopamine $\mathrm{D}(1 / 5)$ antagonist SCH 23390 on the acquisition of conditioned fear. Pharmacol Biochem Behav 66:573-578.

Joshua M, Adler A, Mitelman R, Vaadia E, Bergman H (2008) Midbrain dopaminergic neurons and striatal cholinergic interneurons encode the difference between reward and aversive events at different epochs of probabilistic classical conditioning trials. J Neurosci 28:11673-11684.

Kalivas PW, Duffy P (1995) Selective activation of dopamine transmission in the shell of the nucleus accumbens by stress. Brain Res 675:325-328.

Kelly MA, Rubinstein M, Asa SL, Zhang G, Saez C, Bunzow JR, Allen RG, Hnasko R, Ben-Jonathan N, Grandy DK, Low MJ (1997) Pituitary lactotroph hyperplasia and chronic hyperprolactinemia in dopamine D2 receptor-deficient mice. Neuron 19:103-113.

Koch M (1999) The neurobiology of startle. Prog Neurobiol 59:107-128. 
Kröner S, Rosenkranz JA, Grace AA, Barrionuevo G (2005) Dopamine modulates excitability of basolateral amygdala neurons in vitro. J Neurophysiol 93:1598-1610.

Lalumiere RT, Nguyen LT, McGaugh JL (2004) Post-training intrabasolateral amygdala infusions of dopamine modulate consolidation of inhibitory avoidance memory: involvement of noradrenergic and cholinergic systems. Eur J Neurosci 20:2804-2810.

LaLumiere RT, Nawar EM, McGaugh JL (2005) Modulation of memory consolidation by the basolateral amygdala or nucleus accumbens shell requires concurrent dopamine receptor activation in both brain regions. Learn Mem 12:296-301.

Lammel S, Hetzel A, Häckel O, Jones I, Liss B, Roeper J (2008) Unique properties of mesoprefrontal neurons within a dual mesocorticolimbic dopamine system. Neuron 57:760-773.

Lamont EW, Kokkinidis L (1998) Infusion of the dopamine D1 receptor antagonist SCH 23390 into the amygdala blocks fear expression in a potentiated startle paradigm. Brain Res 795:128-136.

Laviolette SR, Lipski WJ, Grace AA (2005) A subpopulation of neurons in the medial prefrontal cortex encodes emotional learning with burst and frequency codes through a dopamine $\mathrm{D}_{4}$ receptor-dependent basolateral amygdala input. J Neurosci 25:6066-6075.

Lemon N, Manahan-Vaughan D (2006) Dopamine $\mathrm{D}_{1} / \mathrm{D}_{5}$ receptors gate the acquisition of novel information through hippocampal long-term potentiation and long-term depression. J Neurosci 26:7723-7729.

Maren S (2003) The amygdala, synaptic plasticity, and fear memory. Ann N Y Acad Sci 985:106-113.

Maren S, Quirk GJ (2004) Neuronal signalling of fear memory. Nat Rev Neurosci 5:844-852.

Margolis EB, Lock H, Chefer VI, Shippenberg TS, Hjelmstad GO, Fields HL (2006) Kappa opioids selectively control dopaminergic neurons projecting to the prefrontal cortex. Proc Natl Acad Sci U S A 103:2938-2942.

Margolis EB, Mitchell JM, Ishikawa J, Hjelmstad GO, Fields HL (2008) Midbrain dopamine neurons: projection target determines action potential duration and dopamine $\mathrm{D}_{2}$ receptor inhibition. J Neurosci 28:8908-8913.

Marowsky A, Yanagawa Y, Obata K, Vogt KE (2005) A specialized subclass of interneurons mediates dopaminergic facilitation of amygdala function. Neuron 48:1025-1037.

McNish KA, Gewirtz JC, Davis M (1997) Evidence of contextual fear after lesions of the hippocampus: a disruption of freezing but not fearpotentiated startle. J Neurosci 17:9353-9360

Missale C, Nash SR, Robinson SW, Jaber M, Caron MG (1998) Dopamine receptors: from structure to function. Physiol Rev 78:189-225.

Murphy CA, Pezze M, Feldon J, Heidbreder C (2000) Differential involvement of dopamine in the shell and core of the nucleus accumbens in the expression of latent inhibition to an aversively conditioned stimulus. Neuroscience 97:469-477.

Paxinos G, Watson C (2001) The rat brain in stereotaxic coordinates. San Diego: Academic.

Pezze MA, Feldon J (2004) Mesolimbic dopaminergic pathways in fear conditioning. Prog Neurobiol 74:301-320.

Pezze MA, Bast T, Feldon J (2003) Significance of dopamine transmission in the rat medial prefrontal cortex for conditioned fear. Cereb Cortex 13:371-380.

Ponnusamy R, Nissim HA, Barad M (2005) Systemic blockade of D2-like dopamine receptors facilitates extinction of conditioned fear in mice. Learn Mem 12:399-406.

Ralph RJ, Varty GB, Kelly MA, Wang YM, Caron MG, Rubinstein M, Grandy DK, Low MJ, Geyer MA (1999) The dopamine $\mathrm{D}_{2}$, but not $\mathrm{D}_{3}$ or $\mathrm{D}_{4}$, receptor subtype is essential for the disruption of prepulse inhibition produced by amphetamine in mice. J Neurosci 19:4627-4633.

Ralph-Williams RJ, Lehmann-Masten V, Otero-Corchon V, Low MJ, Geyer MA (2002) Differential effects of direct and indirect dopamine agonists on prepulse inhibition: a study in $\mathrm{D}_{1}$ and $\mathrm{D}_{2}$ receptor knock-out mice. J Neurosci 22:9604-9611.

Richardson R (2000) Shock sensitization of startle: learned or unlearned fear? Behav Brain Res 110:109-117.

Risbrough VB, Geyer MA, Hauger RL, Coste S, Stenzel-Poore M, Wurst W, Holsboer $\mathrm{F}$ (2009) $\mathrm{CRF}(1)$ and $\mathrm{CRF}(2)$ receptors are required for potentiated startle to contextual but not discrete cues. Neuropsychopharmacology 34:1494-1503.

Rosenkranz JA, Grace AA (2002) Dopamine-mediated modulation of odour-evoked amygdala potentials during pavlovian conditioning. Nature 417:282-287.

Schultz W (2002) Getting formal with dopamine and reward. Neuron 36:241-263.

Schwarzkopf SB, Mitra T, Bruno JP (1992) Sensory gating in rats depleted of dopamine as neonates: potential relevance to findings in schizophrenic patients. Biol Psychiatry 31:759-773.

Schwarzkopf SB, Bruno JP, Mitra T (1993) Effects of haloperidol and SCH 23390 on acoustic startle and prepulse inhibition under basal and stimulated conditions. Prog Neuropsychopharmacol Biol Psychiatry 17:1023-1036.

Sigala S, Missale C, Spano P (1997) Opposite effects of dopamine D2 and D3 receptors on learning and memory in the rat. Eur J Pharmacol 336: $107-112$.

Sigurdsson T, Doyère V, Cain CK, LeDoux JE (2007) Long-term potentiation in the amygdala: a cellular mechanism of fear learning and memory. Neuropharmacology 52:215-227.

Smith DR, Striplin CD, Geller AM, Mailman RB, Drago J, Lawler CP, Gallagher M (1998) Behavioural assessment of mice lacking D1A dopamine receptors. Neuroscience 86:135-146.

Swant J, Wagner JJ (2006) Dopamine transporter blockade increases LTP in the CA1 region of the rat hippocampus via activation of the D3 dopamine receptor. Learn Mem 13:161-167.

Swerdlow NR, Shoemaker JM, Kuczenski R, Bongiovanni MJ, Neary AC Tochen LS, Saint Marie RL (2006) Forebrain D1 function and sensorimotor gating in rats: effects of D1 blockade, frontal lesions and dopamine denervation. Neurosci Lett 402:40-45.

Szczypka MS, Rainey MA, Kim DS, Alaynick WA, Marck BT, Matsumoto AM, Palmiter RD (1999) Feeding behavior in dopamine-deficient mice. Proc Natl Acad Sci U S A 96:12138-12143.

Wise RA (2004) Dopamine, learning and motivation. Nat Rev Neurosci 5:483-494.

Zhou QY, Palmiter RD (1995) Dopamine-deficient mice are severely hypoactive, adipsic, and aphagic. Cell 83:1197-1209.

Zweifel LS, Argilli E, Bonci A, Palmiter RD (2008) Role of NMDA receptors in dopamine neurons for plasticity and addictive behaviors. Neuron 59: $486-496$. 